\title{
Management of strangulated abdominal wall hernias with mesh; early results
}

\author{
Mustafa Ozbagriacik ${ }^{1}$, Gurhan Bas ${ }^{1}$, Fatih Basak ${ }^{1}$, Abdullah Sisik ${ }^{1}$, Aylin Acar ${ }^{1}$, \\ Ilyas Kudas ${ }^{1}$, Metin Yucel ${ }^{1}$, Adnan Ozpek ${ }^{1}$, Orhan Alimoglu² \\ ${ }^{1}$ Department of General Surgery, Umraniye Training and Research Hospital, Istanbul, Turkey \\ 2Department of General Surgery, Medeniyet University Faculty of Medicine, Goztepe Training and Research Hospital, \\ Istanbul, Turkey
}

\begin{abstract}
OBJECTIVE: Surgery for abdominal wall hernias is a common procedure in general surgery practice. The main causes of delay for the operation are comorbid problems and patient unwillingness, which eventually, means that some patients are admitted to emergency clinics with strangulated hernias. In this report, patients who admitted to the emergency department with strangulated adominal wall hernias are presented together with their clinical management.
\end{abstract}

METHODS: Patients who admitted to our clinic between January 2009 and November 2011 and underwent emergency operation were included in the study retrospectively. Demographic characteristics, hernia type, length of hospital stay, surgical treatment and complications were assessed.

RESULTS: A total 81 patients (37 female, 44 male) with a mean age of $52.1 \pm 17.64$ years were included in the study. Inguinal, femoral, umbilical and incisional hernias were detected in 40, 26, 9 and 6 patients respectively. Polypropylene mesh was used in 75 patients for repair. Primary repair without mesh was used in six patients. Small bowel $(n=10 ; 12.34 \%)$, omentum ( $n=19 ; 23.45 \%)$, appendix $(n=1 ; 1.2 \%)$ and Meckel's diverticulum $(n=1$; $1.2 \%$ ) were resected. Median length of hospital stay was 2 (1-7) days. Surgical site infection was detected in five $(6.2 \%)$ patients. No significant difference was detected for length of hospital stay and surgical site infection in patients who had mesh repair ( $p=0.232$ and 0.326 respectively).

CONCLUSION: The need for bowel resection is common in strangulated abdominal wall hernias which undergo emergency operation. In the present study, an increase of morbidity was seen in patients who underwent bowel resection. No morbidity was detected related to the usage of prosthetic materials in repair of hernias. Hence, we believe that prosthetic materials can be used safely in emergency cases.

Key words: Abdominal hernia; emergency treatment; inguinal hernia

Received: November 26, 2014 Accepted: February 11, 2015 Online: April 24, 2015

Correspondence: Dr. Fatih BASAK. Umraniye Egitim ve Arastirma Hastanesi, Genel Cerrahi Klinigi, Elmali Kent Mahallesi, Adem Yavuz Cad., No: 1, Umraniye, Istanbul, Turkey.

Tel: +90 216 - 6321818 e-mail: fatihbasak@gmail.com

(c) Copyright 2015 by Istanbul Northern Anatolian Association of Public Hospitals - Available online at www.kuzeyklinikleri.com 
$\mathrm{I}$ n studies performed in our country etiologies of bowel obstruction are very diverse. Increase in intestinal adhesions encountered in socioeconomically developed regions is remarkable. Strangulated abdominal wall hernia is one of the frequent referrals to emergency services, and it is a predominant cause of intestinal obstruction in our country [1]. In patients whose hernias are reduced spontaneously, elective surgery is recommended to be performed as soon as possible. Morbidity rates due to emergency surgery can be higher than those of the elective surgery. The most important complications of abdominal wall hernias can be considered as incarceration and strangulation $[1,2]$. The safety and reliability of prosthetic mesh usage is still a debatable subject especially in patients who require bowel resection [3]. The objective of our study is to analyse clinical outcomes of patients operated in our clinic with the indication of strangulated abdominal wall hernias.

\section{MATERIALS AND METHODS}

Patients who consulted to our clinic between January 2009, and November 2011, and operated urgently with the indication of abdominal wall hernia were retrospectively included in the study. Patients' data were obtained from hospital information system and patients' files. Demographic characteristics, types of hernias, contents of hernial sacs, hernia repair methods applied were recorded. The patients were categorized based on types of hernia as inguinal, femoral, umbilical, and incisional hernias. Surgical notes were examined in detail, and additional pathologies encountered during operation were evaluated. Additional interventions were examined in detail. Preoperative duration of complaints of strangulation, length of hospital stay, complications developed within postoperative one month, morbidities and mortalities were recorded, and affecting factors were examined. Patients whose medical files were not available, and patients with missing data were excluded from the study.

\section{Statistical evaluation}

For statistical evaluation of the results obtained, NCSS (Number Cruncher Statistical System)
2007\&PASS (Power Analysis and SampleSize), and 2008 Statistical Software (Utah, USA) programs were used. Descriptive statistics, means \pm standard deviations for continious variables, and numbers, and percentages for categorical data were used for analysis of study data. Parametric data with normal distribution were evaluated using t-test, and Anova. Kruskal-Wallis test was employed for intergroup comparisons of data without normal distribution. The group which demonstrated differences was determined by using Mann Whitney-U test. Chisquare test, and Fisher's exact test were used for the comparison of qualitative data. The results were evaluated within $95 \%$ confidence interval, and at a significance level of $\mathrm{p}<0.05$.

\section{RESULTS}

During the study period, among a total of 1367 cases who had undergone elective abdominal wall hernia repairs, $102(7.4 \%)$ patients had been operated urgently for strangulated abdominal wall hernias. Twenty-one patients were excluded from the study because of missing data. A total of 81 patients were included in the study. Study population consisted of 37 female, and 44 male patients, with a mean age of $52.1 \pm 17.64$ (range, 20-92) years.

The patients had strangulated inguinal $(n=40$; $49,4)$, umbilical $(n=26 ; 32.1 \%)$, femoral $(n=9$; $11.15)$, and incisional $(n=6 ; 7.4 \%)$ hernias (Table 1) In comparisons among types of hernias, differences between male, and female patients were detected, while any difference between age groups was not found ( $p=0.001$, and 0.973 , respectively). Especially in inguinal hernias male gender dominancy (male/female $=4.7$ ) was remarkable, while in other types of hernias female gender predominance was more frequently seen.

Any difference was not detected between types of hernias as for the preoperative onset of complaints related to strangulation $(p=0.079)$. A total of 31 $(38.2 \%)$ patients had undergone various organ resections. Small bowel ( $\mathrm{n}=10,12.3 \%)$, and omentum $(n=19 ; 23.4 \%)$ resections were performed. In one patient perforated appendix was detected in hernial sac which necessitated appendectomy (1.2\%), 
TABLE 1. Some demographic details of the groups based on hernia types

\begin{tabular}{|c|c|c|c|c|c|}
\hline & Inguinal & Femoral & Umbilical & Incisional & $\mathrm{p}$ \\
\hline Number of patients & 40 & 9 & 26 & 6 & \\
\hline Male/female ratio & $33 / 7$ & $3 / 6$ & $7 / 19$ & $1 / 5$ & $0.001^{*}$ \\
\hline Age: Mean \pm SD & $51.3 \pm 18.07$ & $52.4 \pm 26.2$ & $52.5 \pm 15.6$ & $54.8 \pm 9.9$ & ${ }^{\beta} 0.973$ \\
\hline (range) & $(22-83)$ & $(26-92)$ & $(20-84)$ & $(42-68)$ & \\
\hline $\begin{array}{l}\text { Preoperative duration of } \\
\text { complaints, median (range) }\end{array}$ & $12(4-36)$ & $8(4-12)$ & $12(4-24)$ & $6.5(5-9)$ & ` 0.079 \\
\hline $\begin{array}{l}\text { Postoperative hospital stay, } \\
\text { days; median (range) }\end{array}$ & $2(1-7)$ & $2(1-3)$ & $2(1-6)$ & $2(1-2)$ & ү0.737 \\
\hline Bowel resection **n (\%) & $7(58.3)$ & $2(16.7)$ & $2(16.7)$ & $1(8.3)$ & ${ }^{\mathrm{a}} 1.000$ \\
\hline Surgical site infection $\mathrm{n}(\%)$ & $4(80)$ & $1(20)$ & 0 & 0 & ${ }^{\circ} 0.321$ \\
\hline
\end{tabular}

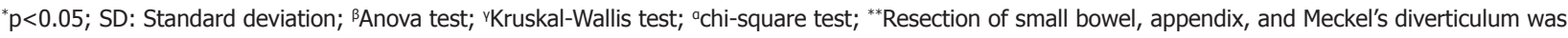
evaluated in combination.

TABLE2. Additional interventions, and their details in diagnostic groups

\begin{tabular}{lcccc} 
Hernia type & $\begin{array}{c}\text { Strangulated organ/ } \\
\text { Additional intervention }\end{array}$ & $\mathrm{n}$ & $\%$ & Contents of the hernial sac \\
\hline Inguinal $(\mathrm{n}=40)$ & Small bowel/Resection & 6 & 15 & Small bowel, sigmoid colon, \\
& Omentum/Resection & 6 & 15 & caecum, tuba uterina, appendix, \\
Femoral $(\mathrm{n}=9)$ & Meckel's Diverticulum/Resection & 1 & 2.5 & omentum, testis, epididymis \\
Umbilical $(\mathrm{n}=26)$ & Small Bowel/Resection & 2 & 22.2 & Small bowel, omentum \\
& Small Bowel/Resection & 2 & 7.6 & Small bowel, omentum \\
Incisional $(\mathrm{n}=6)$ & Omentum/Resection & 11 & 42.3 & Omentum, appendix
\end{tabular}

and in another patient $(1.2 \%)$ hernial sac contained Meckel's diverticulum which required diverticulectomy (Table 2). Median hospital stay was 2 (range, 1-7) days which did not differ among various types of hernias $(p=0.737)$. When all patients who had undergone bowel resection (small bowel, appendix, and Meckel's diverticulum) were evaluated in combination (total n, 12; 14.8\%), any difference between types of hernias was not found, while a significant difference was noted among patients' age, preoperative duration of complaints of strangulation, and length of postoperative hospital stay $(p=1.000$,
0.034, 0.001 and 0.001, respectively) (Table 3).

All patients had received antibiotic prophylaxis with $1 \mathrm{~g}$ IV cefazoline sodium. Superficial site infection was detected in $5(6.2 \%)$ patients, and the patients were cured with medical therapy. Any mortality was not seen in our study group. Type of hernia, age of patients, preoperative duration of strangulation complaints did not differ among patients with surgical site infection, while postoperative hospital stay, and frequency of bowel resection differed significantly among these patients ( $p=0.321,0.108,0.051,0.027$, and 0.001 , respec- 
TABLE 3. Statistical evaluation of the patients who underwent bowel resection

\begin{tabular}{lccc} 
& $\begin{array}{c}\text { Patients who underwent } \\
\text { bowel resection }(n=12)\end{array}$ & $\begin{array}{c}\text { Patients who didn't undergo } \\
\text { bowel resection* }(n=69)\end{array}$ & p \\
\hline $\begin{array}{l}\text { Age }(\text { Mean } \pm \text { SD) } \\
\begin{array}{l}\text { Duration of preoperative complaints } \\
\text { of strangulation (hr): median (range) }\end{array}\end{array}$ & $62 \pm 19.7$ & $50.3 \pm 16.8$ & ${ }^{\beta} 0.001^{* *}$ \\
$\begin{array}{l}\text { Postoperative hospital stay; days: } \\
\text { median (range) }\end{array}$ & $15(6-36)$ & $9(4-24)$ & ${ }^{\beta} 0.001^{* *}$ \\
\hline
\end{tabular}

*Resection of small bowel, appendix, and Meckel's diverticulum was evaluated in combination; SD: Standard deviation; ${ }^{\mathrm{\top} T-t e s t ;}{ }^{\beta}$ Mann-Whitney U test; ${ }^{* *} \mathrm{p}<0.05$.

TABLE 4. Statistical evaluation of surgical site infection

TABLE 5. Statistical evaluation of patients who underwent hernia repair with or without mesh

\begin{tabular}{lccc} 
& $\begin{array}{c}\text { Repair with } \\
\text { mesh }(\mathrm{n}=75)\end{array}$ & $\begin{array}{c}\text { Primary repair without } \\
\text { mesh }(\mathrm{n}=6)\end{array}$ & $\mathrm{p}$ \\
\hline Postoperative hospital stay, days, median (range) & $2(1-6)$ & $2(1-7)$ & ${ }^{\mathrm{a}} 0.232$ \\
Surgical site infection $\mathrm{n}(\%)$ & $4(5.3)$ & $1(16.6)$ & ${ }^{\beta} 0.326$ \\
\hline
\end{tabular}

aMann- Whitney test; ${ }^{\beta}$ Fisher's exact test.

tively) (Table 4).

Inguinal hernia repair was achieved using polypropylene meshes $(n=75,92.5 \%)$ or primary suturing $(n=6 ; 7.5 \%)$. Among patients whose hernias were repaired with meshes, any difference in postoperative hospital stay in days, and development of surgical site infection was not seen $(p=0.232$ and 0.326 , respectively) (Table 5). 
Forty cases (mean age, $51.3 \pm 18.07: 22-83$ yrs) (male, $n=33: 82.5 \%$, and female, $n=7 ; 17.5 \%$ ) with strangulated right $(n=23)$, and left $(n=17)$ inguinal hernias were detected. Indirect $(n=32 ; 80 \%)$, direct $(n=5 ; 12.5 \%)$, and recurrent $(n=3 ; 7.5 \%)$ inguinal hernias were also recorded. Necrotic small bowel segment had been detected in hernial sac of 6 patients who had undergone small bowel resection, and anastomosis, while necrotic omentums of 6 patients had been resected. One patient had undergone diverticulectomy with the indication of Meckel's diverticulum. Strangulated inguinal hernias of the patients were repaired with polypropylene mesh $(n=39 ; 97.5 \%)$ or primarily repair with polypropylene sutures $(n=1 ; 2.5 \%)$.

Strangulated femoral hernias were detected in 6 (66.7\%) female, and $3(33.3 \%)$ male patients, and mean age of the study population was $52.4 \pm 26.2$ (26-92) years. Two patients had undergone bowel resection, and anastomosis because of detection of necrotic small bowel segment in the hernial sac. Strangulated femoral hernias had been repaired either with plug polypropylene mesh $(n=8 ; 11.1 \%)$ or using Mc Vay technique in which conjoined (transversus abdominis and internal oblique) tendon is sutured to the inguinal ligament with polypropylene sutures $(n=1 ; 11.1 \%)$.

Strangulated umbilical hernias were detected in $19(73 \%)$ female, and 7 (27\%) male patients, and the mean age of the study population was $52.5 \pm 15.6$ (20-84) years. Length of the umbilical hernia defects ranged between 2 , and $8 \mathrm{~cm}$. Eleven patients had undergone omentectomy for omental necrosis, while intestinal resection, and anastomosis were performed for 2 patients with small bowel necrosis. Four (15.4\%) patients had undergone primary repair or repair with polypropylene mesh $(\mathrm{n}=22 ; 84.6)$.

Strangulated incisional hernias were detected in 6 (female, $\mathrm{n}=5$, and male, $\mathrm{n}=1$ ) patients with a mean age of $54.8 \pm 9.9(42-68)$ years. One patient underwent omentectomy because of omentum necrosis, and another patient was appendectomized with the indication of appendiceal perforation detected in hernial sac. All incisional hernias were repaired using propylene meshes.

\section{DISCUSSION}

Strangulated abdominal wall hernias requiring surgery are frequently encountered emergency cases. Treatment approach in these patients include urgent surgical exploration, reduction of inguinal hernia, and resection of devitalized tissue in case of need [4]. Achievement of lower mortality, morbidity, and recurrence rates are targeted [5]. Delayed referral of the patient to the hospital or delayed diagnosis bring with them increased mortality, and morbidity rates despite surgical intervention. Diagnosis before the onset of strangulation, and hernia repair under elective conditions can decrease these indicated risks [6]. As has been reported in various publications $5-35 \%$ of the abdominal wall hernias were operated urgently because of strangulation [7]. As detected in the present study, prolonged interval between the onset of the complaints, and referral to the hospital increased the requirement of bowel resection significantly $(p=0,001)$.

Mortality, and morbidity rates in cases with strangulated abdominal wall hernias have been reported as $1.4-13.4 \%$, and $19-30 \%$ respectively. Mortality, and morbidity are related to the development of bowel necrosis secondary to strangulation $[8,9]$. In various studies performed, bowel resection has been reportedly required in $10-15 \%$ of the patients with strangulated abdominal wall hernias [2]. Advanced age, and need for bowel resection have been reportedly associated with increased mortality rates. In various studies, authors reported that advanced age, higher incidence rates of concomitant diseases and delayed referrals increased bowel resection and morbidity rates $[10,11]$. In studies where patients aged $\leq 70$ years with strangulated abdominal wall hernias were urgently operated, higher mortality rates were reported in the advanced age group $[8,11]$. As indicated in various reports, in cases with strangulated abdominal wall hernias, most frequently hernial sac contains small bowel segments [1]. In many studies performed on strangulated abdominal wall hernias which required small bowel resection, a tendency towards increased complication rates was detected [12]. Mean age of our study group was 52.1 years. 
Most frequently omentum (19 cases), and then small bowel (10 cases) were resected because of their strangulation in the hernial sac. Mean age of the patients who had undergone small bowel resection was 59.4 years. Small bowel resection was performed in $12.3 \%$ of all cases with strangulated abdominal wall hernias. Rates of small bowel resection in cases with inguinal, femoral, and umbilical hernias were $15,22.2$, and $7.6 \%$, respectively. Rate of resection in femoral hernias was detectedly higher, however statistical analysis could not be performed because of scarcity of cases with femoral hernias Therefore, larger series are needed to arrive at a conclusion which suggests that increased rates of bowel resection may be required in cases with femoral hernias. When small bowel, appendix, and Meckel's diverticulum were evaluated as a whole, patients who had undergone bowel resection were in their advanced age (mean age, $62 \pm 19.7$ years). Besides they stayed longer in the hospital, and experienced higher number of surgical site infections $(p=0.034,0.001$ and 0.001 , respectively). None of the cases died during perioperative period in our study group. Lack of mortality in our series may be related to the scarce number of our cases.

As reported in studies performed, abdominal wall strangulation is most frequently occurred within inguinal, then umbilical, femoral, and incisional hernia sacs $[1,9,13]$. Still in our study group, in compliance with the literature most frequently (49.4\%) strangulation was detected in inguinal hernia sac. Then in decreasing rates strangulations were seen in umbilical hernia $(32.1 \%)$, femoral hernia $(11.1 \%)$, and incisional hernia $(7.4 \%)$ sacs.

In the literature, incidence of postoperative surgical site infection developed after strangulated abdominal wall hernias has been reported as 3.8-5.3 percent $[2,5]$. In our retrospective study, surgical site infection was noticed in $5(6.2 \%)$ patients Potential increase in morbidity rates with application of meshes in patients who underwent bowel resection or urgently operated has been discussed in various publications [9]. Risk of contamination in patients especially requiring bowel resection has raised suspicions about safe applicability of meshes. However on the other hand, higher risk of recur- rence of primary suture technique has been known irrespective of the primary suture technique [4]. In the literature, some authors have advocated use of prosthetic meshes in the repair of strangulated hernias $[14,15]$. Based on many relevant medical literature reports, antibiotic prophylaxis decreases surgical site infection in cases with strangulated abdominal wall hernias [16]. In the present study, in cases with strangulated hernias operated under emergency conditions, foreign body reaction secondary to application of meshes was not detected. However, if we consider our inadequately shorter postoperative follow-up period, we can not overlook foreign body reaction which might develop against meshes. All patients in our study group underwent routine antibiotic prophylaxis. In our series, higher rates $(92.5 \%)$ of repairs were performed with propylene mesh, which didn't cause any additional morbidity as for duration of hospitalization, and surgical site infection ( $\mathrm{p}=0.232$ and 0.326 , respectively).

In conclusion, emergency surgery should be performed when strangulated abdominal wall hernia is detected before development of impairment of organ blood supply. Achievement of repair under elective conditions in cases with hernia before development of strangulation can decrease the risks of mortality, and morbidity. We are in the opinion that hernia repair with polypropylene mesh can be also applied safely in cases of emergency.

Ethics Committe Approval: Ethics committee approval was not received due to the retrospective nature of the study.

Informed Consent: Written informed consent was not o tained due to the retrospective nature of the study.

Peer-review: Externally peer-reviewed.

Author Contributions: Concept-M.O., G.B., F.B., A.S., A.A., I.K., M.Y., A.O., O.A.; Design-M.O., G.B., F.B., A.S., A.A., I.K., M.Y., A.O., O.A.; Supervision-M.O., G.B., F.B.; Data collection and/or processing-M.O., G.B., F.B., A.S., A.A., I.K.; Analyse and/or interpretation-M.O., G.B., F.B., A.S., A.A., A.O., O.A.; Literature Review-M.O., G.B., F.B., M.Y., A.O., O.A.; Writing-M.O., G.B., F.B., A.S., A.A., I.K., M.Y., A.O., O.A.; Critical review-M.O., G.B., F.B., A.S., A.A., I.K., M.Y., A.O., O.A.

Conflict of Interest: No conflict of interest was declared by the authors.

Financial Disclosure: The authors declared that this study has received no financial support. 


\section{REFERENCES}

1. Akçakaya A, Alimoğlu O, Hevenk T, Baş G, Sahin M. Mechanical intestinal obstruction caused by abdominal wall hernias. [Article in Turkish] Ulus Travma Derg 2000;6:260-5.

2. Kulah B, Kulacoglu IH, Oruc MT, Duzgun AP, Moran M, Ozmen MM, et al. Presentation and outcome of incarcerated external hernias in adults. Am J Surg 2001;181:101-4. CrossRef

3. Derici H, Unalp HR, Nazli O, Kamer E, Coskun M, Tansug T, et al. Prosthetic repair of incarcerated inguinal hernias: is it a reliable method? Langenbecks Arch Surg 2010;395:575-9. CrossRef

4. Nieuwenhuizen J, van Ramshorst GH, ten Brinke JG, de Wit T, van der Harst E, Hop WC, et al. The use of mesh in acute hernia: frequency and outcome in 99 cases. Hernia 2011;15:297-300.

5. Çağlayan K, Çelik A. Strangülasyon nedeni ile ameliyat edilmiş karın duvarı fitıkları. Tıp araştırmaları dergisi 2011;9:29-33.

6. Ohene-Yeboah M. Strangulated external hernias in Kumasi. West Afr J Med 2003;22:310-3.

7. Derici H, Unalp HR, Bozdag AD, Nazli O, Tansug T, Kamer E. Factors affecting morbidity and mortality in incarcerated abdominal wall hernias. Hernia 2007;11:341-6. CrossRef

8. Ezer A, Calışkan K, Colakoğlu T, Parlakgümüş A, Belli S, Tarım A. Factors affecting morbidity in urgent repair of abdominal wall hernia with intestinal incarceration in adults. Ulus Travma Acil Cerrahi Derg 2011;17:344-8. CrossRef

9. Kurt N, Oncel M, Ozkan Z, Bingul S. Risk and outcome of bowel resection in patients with incarcerated groin hernias: ret- rospective study. World J Surg 2003;27:741-3. CrossRef

10. Alvarez JA, Baldonedo RF, Bear IG, Solís JA, Alvarez P, Jorge JI. Incarcerated groin hernias in adults: presentation and outcome. Hernia 2004;8:121-6. CrossRef

11. Martínez-Serrano MA, Pereira JA, Sancho JJ, López-Cano M, Bombuy E, Hidalgo J; Study Group of Abdominal Hernia Surgery of the Catalan Society of Surgery. Risk of death after emergency repair of abdominal wall hernias. Still waiting for improvement. Langenbecks Arch Surg 2010;395:551-6. CrossRef

12. Kekeç Y, Alparslan A, Demirtaş S, Ezici H, Altınay R. The Effects of Strangulation on Morbidity and Mortality in Irreductible Hernias. Ulusal Cerrahi Dergisi 1993;9:128-31.

13. Rai S, Chandra SS, Smile SR. A study of the risk of strangulation and obstruction in groin hernias. Aust N Z J Surg 1998;68:6504. CrossRef

14. Legnani GL, Rasini M, Pastori S, Sarli D. Laparoscopic transperitoneal hernioplasty (TAPP) for the acute management of strangulated inguino-crural hernias: a report of nine cases. Hernia 2008;12:185-8. CrossRef

15. Bessa SS, Katri KM, Abdel-Salam WN, Abdel-Baki NA. Early results from the use of the Lichtenstein repair in the management of strangulated groin hernia. Hernia 2007;11:239-42. CrossRef

16. Yerdel MA, Akin EB, Dolalan S, Turkcapar AG, Pehlivan M, Gecim IE, et al. Effect of single-dose prophylactic ampicillin and sulbactam on wound infection after tension-free inguinal hernia repair with polypropylene mesh: the randomized, double-blind, prospective trial. Ann Surg 2001;233:26-33. CrossRef 